\title{
DEPENDENCE OF MECHANICAL AND MAGNETIC PROPERTIES OF HYPEREUTECTOID STEEL ON EXCESS CEMENTITE MORPHOLOGY
}

\author{
S. V. Burov*, Yu. V. Khudorozhkova \\ Institute of Engineering Science, Ural Branch of the Russian Academy of Sciences, 620049, 34 Komsomolskaya st., \\ Ekaterinburg, Russian Federation \\ *Corresponding author. E-mail: burchitai@ mail.ru; address for correspondence: ul. Komsomolskaya 34, 620049, \\ Ekaterinburg, Russian Federation. Tel.:+7 343 3753583; fax: +7 3433745330
}

A set of physical and mechanical properties of the U13 steel depending on the morphology of the excess hypereutectoid cementite phase has been revealed. Excess cementite is represented by globules with uniform or layered distribution, by Widmanstätten type needles and by a cementite network. Samples with layer distribution of globular excess cementite demonstrate a better set of strength and plasticity, whereas the worst set of properties are characteristic of samples with a cementite network. The investigated magnetic properties can serve as a basis for the development of methods for electromagnetic testing of excess cementite morphology and the level of strength of hypereutectoid steels after thermomechanical treatment. structure.

Keywords: cementite, cementite network, Widmanstätten cementite, hypereutectoid steel,

DOI: $10.17804 / 2410-9908.2016 .6 .092-099$

\section{References}

1. Makarov A.V., Kogan L.Kh., Schastlivtsev V.M., Kolobylin Yu.M., Yakovleva I.L., Gorkunov E.S., Tabatchikova T.I. Feasibility of testing hardness and wear resistance of eutectoid high-carbon steels with the structure of thin-plate pearlite by magnetic and electromagnetic methods. Russian Journal of Nondestructive Testing, 2000, vol. 36, no. 8, pp. 539-550.

2. Chulkina A.A., Ul'Yanov A.I., Arsentieva N.B., Zagainov A.V., Gorkunov E.S., Zadvorkin S.M., Somova V.M. The role of cementite in the formation of magnetic hysteresis properties of plastically deformed high-carbon steels: II. Magnetic properties of patented wire made of steel 70. Russian Journal of Nondestructive Testing, 2006, vol. 42, no. 7, pp. 460-467. DOI: $10.1134 / \mathrm{S} 1061830906070059$.

3. Gorkunov E.S. Magnetic Structural-Phase Analysis as Applied to Diagnosing and Evaluating the Lifetime of Products and Structural Components. Part 1. Diagnostics, Resource and Mechanics of materials and structures, 2015, iss. 1, pp. 6-40. DOI: 10.17804/24109908.2015.1.006-040. Available at: http://dream-journal.org/issues/2015-1/2015-1_19.html.

4. Gorkunov E.S. Magnetic Structural-phase Analysis. Part II. Diagnostics, Resource and Mechanics of materials and structures, 2015, iss. 3, pp. 6-50. DOI: 10.17804/24109908.2015.3.006-050. Available at: http://dream-journal.org/issues/2015-3/2015-3_34.html.

5. Burov S.V., Khudorozhkova Yu.V. Distributional and Morphological Changes in Excess Cementite during Deformation of Hypereutectoid Steels. Diagnostics, Resource and Mechanics of materials and structures, 2015, iss. 6, pp. 80-89. DOI: 10.17804/2410-9908.2015.6.80-89. Available at: http://dream-journal.org/issues/2015-6/2015-6_71.html.

6. Verhoeven J.D., Gibson E.D. The divorced eutectoid transformation in steel. Metallurgical and Materials Transactions A, 1998, vol. 29A, pp. 1181-1189. DOI: 10.1007/s11661-998-0245-4.

7. Burov S.V., Khudorozhkova Yu.V., Ryzhkov M.A. Peculiarities of austenite transformation under continuous cooling of hypereutectoid steel. Obrabotka Metallov, 2013, no. 4 (61), pp. 65-70. (In Russian). 
http://dream-journal.or"]

8. Khudorozhkova Yu.V., Burov S.V. Investigation of the structure and magnetic properties of hypereutectoid steel with different carbide phase morphology. AIP Conference Proceedings, 2016, vol. 1785, iss. 1, pp. 040026. DOI: 10.1063/1.4967083. Available at: http://scitation.aip.org/content/aip/proceeding/aipcp/1785?ver=pdfcov.

9. Plotnikova N.V. Rol morfologii tsementita v obespechenii konstruktivnoy prochnosti uglerodistykh zaevtektoidnykh staley [The Contribution of Cementite Morphology to the Structural Strength of Hypereutectoid Carbon Steels]. PhD thesis synopsis, Novosibirsk, 2004, 19 p. (In Russian).

10. Sukhanov D.A., Arkhangelskiy L.B., Plotnikova N.V. The morphology of the carbides in high-carbon alloys such as damascus steel. Obrabotka metallov, 2016, no. 4 (73), pp. 43-51. DOI: 10.17212/1994-6309-2016-4-43-51. (In Russian).

11. Sukhanov D.A., Arkhangelskiy L.B. Damascus steel microstructure. Metallurgist, 2016, vol. 59, iss. 9, pp. 818-822. DOI: 10.1007/s11015-016-0178-x. 
Подана в журнал: 10.11 .2016

УДК 620.179:620.174:620.172:620.186

DOI: $10.17804 / 2410-9908.2016 .6 .092-099$

\title{
ЗАВИСИМОСТЬ МЕХАНИЧЕСКИХ И МАГНИТНЫХ СВОЙСТВ ЗАЭВТЕКТОИДНОЙ СТАЛИ ОТ МОРФОЛОГИИ ИЗБЫТОЧНОГО ЦЕМЕНТИТА
}

\author{
С. В. Буров*, Ю. В. Худорожкова \\ Федеральное государственное бюджетное учреждение науки Институт машиноведения \\ Уральского отделения Российской академии наук, ул. Комсомольская, 34, Екатеринбург, Российская Федераџия \\ *Ответственный автор. Электронная почта: burchitai@mail.ru; адрес для переписки: ул. Комсомольская, 34, \\ 620049, Екатеринбург, Российская Федерация. Телефон: +7 (343) 375-35-83; факс: +7 (343) 374-53-30
}

Определен комплекс физико-механических свойств стали У13 с различной морфологией избыточной карбидной фазы - в виде равномерно распределенных глобулей, глобулей с преимущественно слоистым распределением, в виде остатков игл видманштеттова цементита и в виде сетки по границам бывшего аустенитного зерна. Наилучшим комплексом прочности и пластичности обладают образцы со слоистым распределением глобулярного избыточного цементита, а наихудшим - образцы с цементитной сеткой. Исследование магнитных характеристик дало результаты, которые могут быть основой для разработки методик электромагнитного контроля морфологии карбидной фазы и уровня механических характеристик углеродистых заэвтектоидных сталей, подвергнутых термомеханической обработке.

Ключевые слова: цементит, цементитная сетка, видманштеттов иементит, заэвтектоидная сталь, структура.

\section{1. Введение}

Обеспечение высокой износостойкости инструмента и элементов конструкций часто решается применением заэвтектоидных сталей. Возрастание объемной доли карбидов приводит к увеличению износостойкости. Важную роль для характеристик вязкости и пластичности заэвтектоидных сталей играет морфология избыточного цементита, а его дисперсность и характер распределения могут влиять на характеристики износостойкости, что ставит важную задачу управления морфологией и дисперсностью карбидной фазы, а также установлением взаимосвязей между морфологией и свойствами стали. Обеспечение различного уровня механических характеристик за счет обеспечения необходимой структуры карбидной подсистемы делает необходимым разработку неразрушающих методов контроля структуры на основе измерения физических характеристик материалов. Согласно современным представлениям, морфология цементита в составе эвтектоида накладывает существенный отпечаток на магнитные характеристики стали. Измерение магнитных свойств, прежде всего коэрцитивной силы, может быть основой для прогнозирования прочности перлитной стали, поскольку коэрцитивная сила чувствительна как к дисперсности перлита, так и морфологии карбидных (и конечно ферритных) частиц в нем [1-4].

Влияние морфологии и характера распределения избыточного цементита на магнитные свойства заэвтектоидных сталей изучено в меньшей степени, однако имеются сравнительные данные по глобулярному и сетчатому избыточному цементиту [2-3].

Из литературных источников и собственных данных авторов известно, что в заэвтектоидных сталях могут быть реализованы различные морфологии избыточного цементита: глобулярная, в виде сетки и в виде цементитных игл (пластин) видманштеттовой природы $[5,10]$. Известно, что в литом состоянии избыточный цементит может быть представлен и в виде неравновесного ледебурита, однако формирование этого ледебурита в заэвтектоидной стали обеспечивается только при кристаллизации и не свойственно для большинства ком-

Burov S.V. et al. / Dependence of mechanical and magnetic properties of hypereutectoid steel on excess cementite morphology 
мерческих сталей, поставляемых в деформированном состоянии $[5,10,11]$. Характер распределения глобулярного цементита также может различаться - быть равномерным или носить неравномерный характер, глобули избыточного цементита могут быть распределены слоями или строчками по границам бывшего аустенитного зерна. Таким образом, для прогнозирования эксплуатационных механических свойств важным является определение влияния морфологии и характера распределения избыточного цементита: экспериментальная реализация этого возможна при варьировании избыточной карбидной фазы при постоянной морфологии основного металла. Исследование изменения механических свойств и магнитных характеристик в зависимости от характера распределения и морфологии избыточного цементита может служить основой для прогнозирования механических свойств стали на основании данных неразрушающего контроля.

Цель настоящей работы - выявить влияние морфологии избыточного цементита на уровень прочности, пластичности и магнитные характеристики стали.

\section{2. Материалы и методика исследования}

В качестве материала исследования выбрана заэвтектоидная углеродистая сталь У13, химического состава (в мас. \%): $\mathrm{C}-1,27 \% ; \mathrm{Si}-0,22 \% ; \mathrm{Mn}-0,27 \%$; $-0,014 \%$; $\mathrm{S}-0,009 \%$.

Для определения влияния морфологии избыточного цементита на коэрцитивную силу стояла задача получить различную морфологию избыточного цементита при близкой или одинаковой морфологии и дисперсности эвтектоидной матрицы заэвтектоидной стали. Однообразность матрицы может давать возможность для оценки вклада в магнитные свойства только структуры избыточного цементита.

Решение этой задачи стало возможным с разработкой четырех режимов термообработки, описанных нами ранее в работе [8]. Первая часть каждого режима была высокотемпературной и включала нагрев выше $\mathrm{A}_{\mathrm{Cm}}$, для обеспечения необходимой морфологии избыточного цементита в зависимости от скорости охлаждения, итоговая часть каждого режима представляла собой охлаждение на воздухе и обеспечивала единство структуры матрицы. Это итоговое охлаждение проводили с температуры $780{ }^{\circ} \mathrm{C}$, лежащей в межкритическом интервале между $\mathrm{A}_{\mathrm{Cm}}$ и $\mathrm{A}_{1}$. Сложность получения одинаковой структуры матрицы заключается в том, что зародышами для роста перлита могут являться сферические частицы избыточного цементита [6].

Режим 1: Нормализация с температуры нагрева $1160{ }^{\circ} \mathrm{C}$, прокатка с обжатием в 3 раза в интервале $800 \ldots 700{ }^{\circ} \mathrm{C}$. Итоговая обработка - нормализация с $780{ }^{\circ} \mathrm{C}$. В структуре получено преимущественно слоистое распределение глобулей избыточного цементита. Механизм формирования слоистого распределения избыточного глобулярного цементита описан нами ранее в работе [5] и основан на формировании состоящего из тонких пластин игольчатого цементита и его последующем дроблением и сфероидизации при деформировании в интервале между $\mathrm{A}_{\mathrm{Cm}}$ и $\mathrm{A}_{1}$.

Режим 2: Нормализация с температуры нагрева $900^{\circ} \mathrm{C}$, вторая нормализация с температуры $850{ }^{\circ} \mathrm{C}$, отжиг при $650^{\circ} \mathrm{C}, 1$ ч. Итоговая обработка - нормализация с $780{ }^{\circ} \mathrm{C}$. В структуре равномерно распределенные избыточные карбиды.

Режим 3: Нормализация с температуры нагрева $1100{ }^{\circ} \mathrm{C}$. Итоговая обработка - нормализация с $780{ }^{\circ} \mathrm{C}$. В структуре имеются игольчатые избыточные карбиды. Нормализация с очень высоких температур при значительном перегреве аустенита приводит к формированию избыточного цементита в виде пластин видманштеттова типа. Особенности такого распада описаны в работах [7, 9].

Режим 4: Отжиг при температуре $950{ }^{\circ} \mathrm{C}, 1$ ч с охлаждением с печью и итоговая обработка - нормализация с $780{ }^{\circ} \mathrm{C}$. Отжиг с медленным охлаждением был проведен с целью формирования сетки избыточного цементита по границам бывших аустенитных зерен.

Burov S.V. et al. / Dependence of mechanical and magnetic properties of hypereutectoid steel on excess cementite morphology 
Для всех четырех режимов итоговая нормализация обеспечила распад матрицы на глобулярный перлит. Несмотря на то, что итоговой термической обработкой всех режимов являлась нормализация с температуры нагрева $780{ }^{\circ} \mathrm{C}$ для получения одинаковой структуры перлитной основы стали, на перлитное превращение накладывает отпечаток морфология избыточного цементита. В случае с цементитной сеткой избыточный цементит не служит зародышеобразующей фазой при образовании перлита, что приводит к формированию некоторой доли пластинчатого перлита при этом режиме.

Физические характеристики определяли на магнитно-измерительном комплексе Remagraph C-500 на образцах длиной 120 мм и диаметром 6 мм.

Образцы, полученные по четырем описанным режимам, были подвергнуты прочностным испытаниям на трехточечный изгиб и на растяжение. Образцы в обоих случаях испытывали на испытательной машине Instron 8801. Образцы длиной 55 мм и сечением $10 \times 10$ мм с надрезом для испытаний на трехточечный изгиб имели $\mathrm{V}$-образный надрез. Испытания на растяжение производили по ГОСТ 1497-84 (ИСО 6892-84) на образцах № 4 типа VII.

\section{3. Результаты и обсуждение}

В заэвтектоидной углеродистой стали У13 могут быть реализованы различные морфологии и характеры распределения избыточного цементита. Цементит может быть представлен в виде двухмерных построений, таких как сетка по границам и пластины видманштеттова типа в объемах бывших аустенитных зерен. Глобулярная морфология избыточного цементита может характеризоваться как равномерным распределением глобулей цементита, так и неревномерным, с образованием слоев из глобулей.

Результаты металлографического анализа образцов описаны нами ранее в работе [8]. В результате термообработки, комбинированной с деформированием в интервале между $\mathrm{A}_{\mathrm{Cm}}$ и $\mathrm{A}_{1}$ получено слоистое распределение глобулей избыточного цементита в матрице глобулярного перлита. Режим термообработки второй группы образцов обеспечил равномерное распределение глобулярного избыточного цементита в матрице глобулярного перлита. Пластины цементита видманштеттова типа, частично распавшиеся при итоговой нормализации, находящиеся в матрице из глобулярного перлита характерны для группы 3. Необходимо отметить, что формирование глобулярного перлита может быть охарактеризовано прохождением распада аустенита по механизму разведенного эвтектоидного превращения, описанного в работе [6]. В образцах четвертой группы структура матрицы образована как смесь глобулярного и пластинчатого перлита. Разведенное эвтектоидное превращение не прошло в полной степени, поскольку при распаде аустенита практически не было частиц избыточного цементита внутри объемов, ограниченных цементитной сеткой и почти весь избыточный цементит был сосредоточен на границах бывших аустенитных зерен. Доля мелкопластинчатого перлита в структуре составляет в разных зонах образцов от 20 до $30 \%$.

Для разработки методик электромагнитного контроля морфологии карбидной фазы и уровня механических характеристик углеродистых заэвтектоидных сталей, подвергнутых термомеханической обработке был проведен комплекс исследования физико-механических свойств.

В работе выявлено влияние различных морфологий избыточного цементита в стали У13 на коэрцитивную силу, для определения возможности неразрушающего инструментального контроля подсистемы избыточного карбида.

Поскольку наиболее чувствительными физическими характеристиками к изменению параметров структуры являются коэрцитивная сила $-H_{\mathrm{c}}$, остаточная индукция $B_{\mathrm{r}}$ и максимальная магнитная проницаемость $\mu_{\max }$, в табл. 1 приведены результаты измерения данных физических характеристик. 
Таблица 1 - Физические характеристики исследуемой стали

\begin{tabular}{|c|c|c|c|}
\hline № группы & $H_{\mathrm{c}}, \mathrm{A} / \mathrm{cm}$ & $\mu_{\max }$ & $B_{\mathrm{r}}, \mathrm{T}$ \\
\hline 1 & $10,8 \pm 0,2$ & 460 & $1,18 \pm 0,02$ \\
\hline 2 & $13,6 \pm 0,15$ & 392 & $1,19 \pm 0,01$ \\
\hline 3 & $14,0 \pm 0,3$ & 392 & $1,21 \pm 0,01$ \\
\hline 4 & $11,3 \pm 0,2$ & 404 & $1,05 \pm 0,01$ \\
\hline
\end{tabular}

Из данных табл. 1 видно, что слоистое распределение глобулей избыточного цементита характеризуется максимальной магнитной проницаемостью и минимальной коэрцитивной силой. По данным работы [6], коэрцитивная сила для перлита, сфероидизированного (при отжиге) на 75 \%, составляет 11,5 А/см. Измеренная нами величина составила для этого режима обработки $11,3 \pm 0,2 \mathrm{~A} / \mathrm{cm}$, т. е. можно говорить о незначительном влиянии цементитной сетки на величину коэрцитивной силы.

Несмотря на увеличение доли пластинчатого перлита, обладающего большей коэрцитивной силой $H_{\mathrm{c}}$, коэрцитивная сила составляет для первой группы образцов $10,8 \pm 0,2 \mathrm{~A} / \mathrm{cm}$, для второй группы 13,6 \pm 0,15 A/cм, для третьей группы 14,0 \pm 0,3 A/см, для четвертой группы $11,3 \pm 0,2 \mathrm{~A} / \mathrm{cm}$. Такая разница в значениях коэрцитивной силы может быть вызвана различиями в морфологии и характере распределения избыточного цементита.

Данные исследования механических свойств представлены в табл. 2 и 3, доверительный интервал характеристик не превышает $\pm 2,5 \%$ от измеренных величин.

Таблица 2 - Механические свойства нормализованной с $780{ }^{\circ} \mathrm{C}$ стали У 13 с различным характером распределения избыточных карбидных частиц, полученные из испытаний на трехточечный изгиб

\begin{tabular}{|l|c|c|c|}
\hline $\begin{array}{c}\text { Морфология и характер } \\
\text { распределения избыточ- } \\
\text { ных карбидных частиц }\end{array}$ & $\begin{array}{c}\text { Условный предел } \\
\text { текучести при из- } \\
\text { гибе-0,2\%, МПа }\end{array}$ & $\begin{array}{c}\text { Максимальное } \\
\text { напряжение при } \\
\text { изгибе, МПа }\end{array}$ & $\begin{array}{c}\text { Деформация при мак- } \\
\text { симальной нагрузке } \\
\text { при изгибе, \% }\end{array}$ \\
\hline $\begin{array}{l}\text { Слоистое распределение } \\
\text { глобулей (режим 1), } \\
\text { фронт трещины паралле- } \\
\text { лен слоям }\end{array}$ & 943 & 1304 & 2,47 \\
\hline $\begin{array}{l}\text { Слоистое распределение } \\
\text { глобулей (режим 1), } \\
\text { фронт трещины перпен- } \\
\text { дикулярен слоям }\end{array}$ & 933 & 1270 & 1,72 \\
\hline $\begin{array}{l}\text { Однородное равномерное } \\
\text { распределение глобулей } \\
\text { цементита (режим 2) }\end{array}$ & 1000 & 1338 & 1,42 \\
\hline $\begin{array}{l}\text { Игольчатые избыточные } \\
\text { карбиды (режим 3) }\end{array}$ & 960 & 1353 & 1,83 \\
\hline $\begin{array}{l}\text { Выделение карбида в виде } \\
\text { цементитной сетки } \\
\text { (режим 4) }\end{array}$ & 993 & 1020 & 1,19 \\
\hline
\end{tabular}

При прочностных испытаниях на изгиб и на растяжение выявлено, что уровень прочностных свойств (условный предел текучести и временное сопротивление) стали У13, подвергнутой нормализации с температуры $780^{\circ} \mathrm{C}$, примерно одинаков для различных морфологий избыточной карбидной фазы. 
Таблица 3 - Механические свойства нормализованной с $780{ }^{\circ} \mathrm{C}$ стали У 13 с различным характером распределения избыточных карбидных частиц, полученные при испытаниях на растяжение

\begin{tabular}{|l|c|c|c|c|}
\hline \multicolumn{1}{|c|}{$\begin{array}{l}\text { Характер распределения из- } \\
\text { быточных карбидных частиц }\end{array}$} & $\begin{array}{c}\text { Относительное } \\
\text { удлинение } \varepsilon, \%\end{array}$ & $\begin{array}{c}\text { Относительное } \\
\text { сужение } \psi, \%\end{array}$ & $\sigma_{0,2}$ & $\sigma_{\mathrm{в}}$ \\
\hline $\begin{array}{l}\text { Слоистое распределение } \\
\text { глобулей цементита (режим 1) }\end{array}$ & 20 & 46 & 294 & 542 \\
\hline $\begin{array}{l}\text { Однородное равномерное } \\
\text { распределение глобулей } \\
\text { цементита (режим 2) }\end{array}$ & 20 & 33 & 293 & 533 \\
\hline $\begin{array}{l}\text { Игольчатые избыточные } \\
\text { карбиды (режиму 3) }\end{array}$ & 23 & 36 & 271 & 548 \\
\hline $\begin{array}{l}\text { Выделение карбида в виде } \\
\text { цементитной сетки (режим 4) }\end{array}$ & 14 & 13 & 288 & 551 \\
\hline
\end{tabular}

Показатели пластичности стали У13, характеризующиеся относительным сужением и деформацией при максимальной нагрузке на изгиб, со слоистым распределением глобулярного избыточного цементита значительно превышают показатели пластичности для других морфологий и характера распределений. Наименьшими показателями пластичности обладает сталь с выраженной цементитной сеткой.

\section{Заключение}

1. Разработаны научно-технологические основы целенаправленного управления структурой заэвтектоидной стали, позволяющие путем термомеханической обработок получить слоистое распределение избыточного цементита и тем самым значительно улучшить комплекс механических свойств по сравнению со сталями аналогичного химического состава с изотропной структурой. Показатели пластичности стали У13 со слоистым распределением глобулярного избыточного цементита значительно превышают показатели пластичности для других морфологий и характеров распределений. Так при испытании на растяжение относительное сужение образцов со слоистым распределением глобулей избыточного цементита составило $46 \%$, для других типов образцов $13 . .33 \%$, при изгибе деформация при максимальной нагрузке составила 2,47 \% против $1,19 \ldots 1,83 \%$. Наименьшими показателями пластичности обладает сталь с выраженной цементитной сеткой.

2. При прочностных испытаниях на изгиб и на растяжение выявлено, что уровень прочностных свойств (условный предел текучести и временное сопротивление) стали У13, подвергнутой нормализации с температуры $780{ }^{\circ} \mathrm{C}$, примерно одинаков для различных морфологий избыточной карбидной фазы. Условный предел текучести при растяжении и изгибе для всех исследованных режимов обработки укладывается в интервалы 271...293 МПа и 933...1000 МПа соответственно. Временное сопротивление $\sigma_{\text {в }}$ при растяжении находится в интервале 533...551 МПа.

3. Получены результаты, которые могут явиться основой для разработки методик электромагнитного контроля морфологии карбидной фазы и уровня механических характеристик углеродистых заэвтектоидных сталей, подвергнутых термомеханической обработке. Максимальный уровень пластичности, характерный для слоистого распределения глобулей избыточного цементита, характеризуется максимальной магнитной проницаемостью и минимальной коэрцитивной силой. 


\section{Благодарность}

Работа выполнена в соответствии с государственным заданием (№ ГР 01201354598). При выполнении исследований использовалось оборудование ЦКП «Пластометрия».

\section{Литература}

1. Feasibility of testing hardness and wear resistance of eutectoid high-carbon steels with the structure of thin-plate pearlite by magnetic and electromagnetic methods / A. V. Makarov, L. Kh. Kogan, V. M. Schastlivtsev, Yu. M. Kolobylin, I. L. Yakovleva, E. S. Gorkunov, T. I. Tabatchikova // Russian Journal of Nondestructive Testing. - 2000. - Vol. 36, № 8. P. 539-550.

2. The role of cementite in the formation of magnetic hysteresis properties of plastically deformed high-carbon steels: II. Magnetic properties of patented wire made of steel 70 / A. A. Chulkina, A. I. Ul'Yanov, N. B. Arsentieva, A. V. Zagainov, E. S. Gorkunov, S. M. Zadvorkin, V. M. Somova // Russian Journal of Nondestructive Testing. - 2006. - Vol. 42, № 7. - P. 460-467. DOI: 10.1134/S1061830906070059.

3. Gorkunov E. S. Magnetic Structural-Phase Analysis as Applied to Diagnosing and Evaluating the Lifetime of Products and Structural Components. Part 1 // Diagnostics, Resource and Mechanics of materials and structures. - 2015. - Iss. 1. - P. 6-40. - DOI: 10.17804/24109908.2015.1.006-040. - URL: http://dream-journal.org/issues/2015-1/2015-1_19.html.

4. Gorkunov E. S. Magnetic Structural-phase Analysis. Part II // Diagnostics, Resource and Mechanics of materials and structures. - 2015. - Iss. 3. - P. 6-50. - DOI: 10.17804/24109908.2015.3.006-050. - URL: http://dream-journal.org/issues/2015-3/2015-3_34.html.

5. Burov S. V., Khudorozhkova Yu. V. Distributional and Morphological Changes in Excess Cementite during Deformation of Hypereutectoid Steels // Diagnostics, Resource and Mechanics of materials and structures. - 2015. - Iss. 6. - P. 80-89. - DOI: 10.17804/2410-9908.2015.6.80-89. URL: http://dream-journal.org/issues/2015-6/2015-6_71.html.

6. Verhoeven J. D., Gibson E. D. The divorced eutectoid transformation in steel // Metallurgical and Materials Transactions A. - 1998. - Vol. 29A. - P. 1181-1189. - DOI: 10.1007/s11661998-0245-4.

7. Буров С. В., Худорожкова Ю. В., Рыжков М. А. Особенности распада аустенита при непрерывном охлаждении перегретой заэвтектоидной стали // Обработка металлов (технология, оборудование, инструменты). - 2013. - № 4 (61). - С. 65-70.

8. Khudorozhkova Yu. V., Burov S. V. Investigation of the structure and magnetic properties of hypereutectoid steel with different carbide phase morphology // AIP Conference Proceedings. 2016. - Vol. 1785, iss. 1. - P. 040026. - DOI: 10.1063/1.4967083. - URL: http://dx.doi.org/10.1063/1.4967083.

9. Плотникова Н. В. Роль морфологии цементита в обеспечении конструктивной прочности углеродистых заэвтектоидных сталей : автореф. дис. ... канд. техн. наук. - Новосибирск, 2004. - 19 с.

10. Суханов Д. А., Архангельский Л. Б., Плотникова Н. В. Морфология избыточной карбидной фазы в высокоуглеродистых сплавах типа булат // Обработка металлов (технология, оборудование, инструменты). - 2016. - № 4 (73). - C. 43-51. - DOI: 10.17212/1994-6309-20164-43-51. - ISSN 1994-6309.

11. Sukhanov D. A., Arkhangelskiy L. B. Damascus steel microstructure // Metallurgist. 2016. - Vol. 59, iss. 9. - P. 818-822. - DOI: 10.1007/s11015-016-0178-x. 